Titulo do Trabalho

\title{
A METÁFORA DO EFEITO ESTUFA
}

Nome do Autor (a) Principal

Daniela de Souza Onça

Instituição

Universidade do Estado de Santa Catarina

E-mail de contato

danielaonca@yahoo.com.br

Palavras-chave

Efeito estufa. Dióxido de carbono. Sistema climático

\section{INTRODUÇÃO}

Um importantíssimo ponto a ser frisado quando discutimos a hipótese do aquecimento global é a questão do efeito estufa. Muitas vezes ambos os fenômenos são confundidos quando na realidade são absolutamente distintos e mal conceituados. Neste trabalho, teceremos algumas considerações teóricas a respeito do funcionamento do chamado efeito estufa no sistema climático terrestre.

\section{OBJETIVO GERAL}

Discutir a construção da metáfora do efeito estufa para o sistema climático e apontar suas limitações. 


\section{OBJETIVO ESPECİFICO}

Ressaltar um importante exemplo de necessidade de reformulação de conceitos na Climatologia, com vistas a um entendimento mais adequado do funcionamento do sistema climático.

\section{DISCUSSÃo}

A quantidade média de energia recebida pelo nosso planeta é de cerca de 342 $\mathrm{W} / \mathrm{m}^{2}$ ao longo de um ano. Cerca de $30 \%$ desse total é refletido de volta para o espaço, dos quais dois terços são de responsabilidade das nuvens e aerossóis atmosféricos, e um terço de regiões de albedo elevado, como neve, gelo e desertos. A energia que não é refletida de volta para o espaço é absorvida pela superfície terrestre e pela atmosfera, numa quantidade de aproximadamente $240 \mathrm{~W} / \mathrm{m}^{2}$. Para balancear essa energia incidente, a Terra deve irradiar, em média, a mesma quantidade de energia, o que faz por meio de radiação de onda longa (infravermelho). Para emitir os $240 \mathrm{~W} / \mathrm{m}^{2}$, uma superfície deve ter uma temperatura em torno de $-19^{\circ} \mathrm{C}$, um valor muito abaixo da temperatura estimada da superfície terrestre, de $14^{\circ} \mathrm{C}$. A razão para esse incremento de temperatura é a presença, na atmosfera, de gases que bloqueiam parte da radiação de onda longa que escaparia para o espaço. Este processo é comumente denominado efeito estufa. Os dois gases dominantes da atmosfera, o nitrogênio e o oxigênio, não atuam nesse sentido; mas sim gases presentes em menor quantidade, dos quais os mais importantes são o vapor d'água e o dióxido de carbono (IPCC, 2007, p. 96-97). 


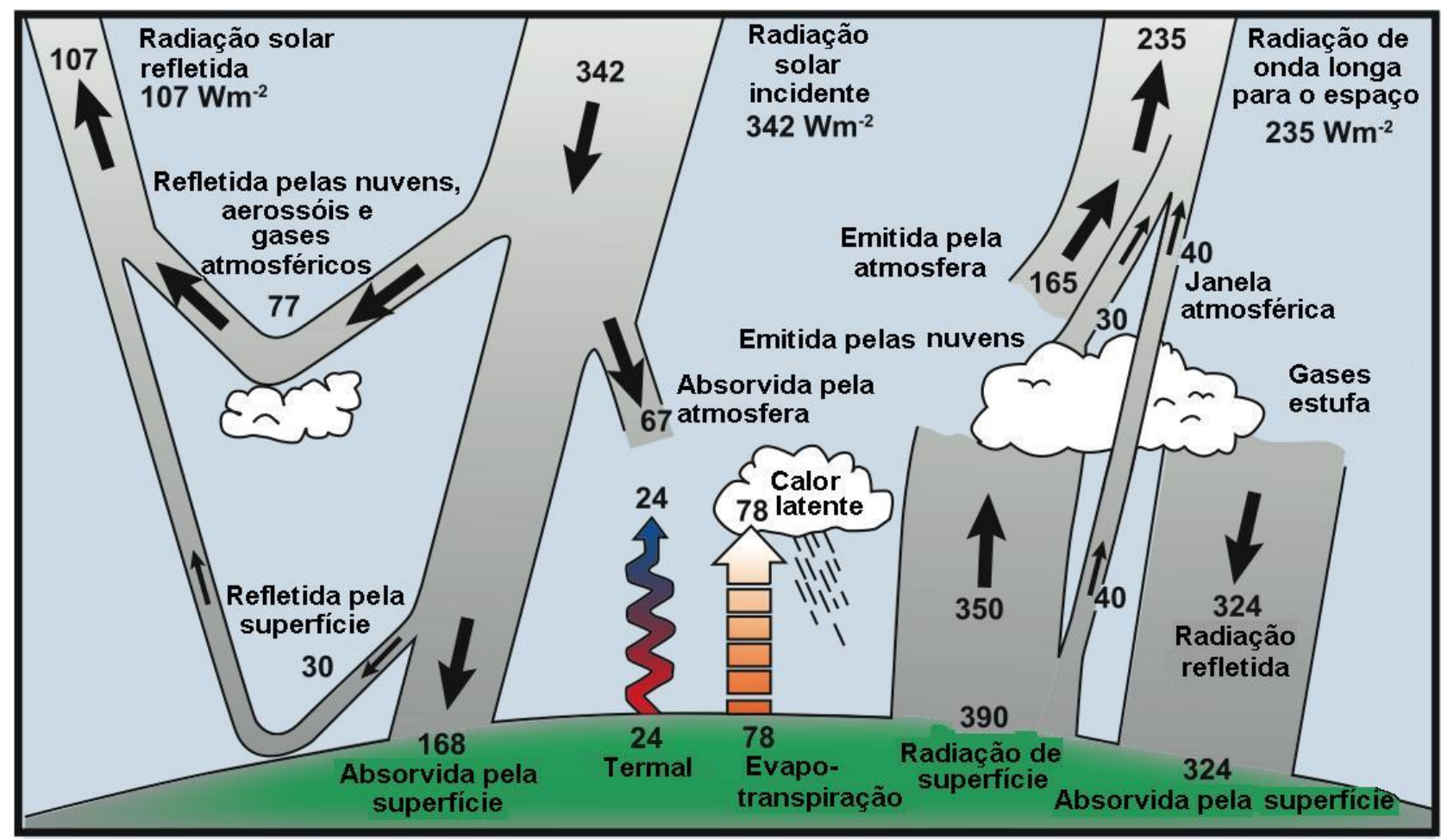

Figura 1 - Estimativa do balanço de energia global anual da Terra (IPCC, 2007, p. 96).

A metáfora do efeito estufa afirma, pois, que a atmosfera terrestre atua como uma estufa de plantas, permitindo a entrada de radiação solar em seu interior, mas bloqueando a saída de radiação infravermelha, elevando assim as temperaturas em seu interior. Tal metáfora é amplamente divulgada para justificar que o aumento das concentrações atmosféricas dos chamados gases estufa intensificaria esse efeito, elevando as temperaturas do planeta tal como aconteceria em uma estufa de plantas. Porém, o que pouco se divulga é que as estufas de plantas se aquecem não pelo fato de sua cobertura impedir a saída de radiação infravermelha. Sua estrutura de vidro, na realidade, interfere muito pouco na regulagem da saída desse tipo de radiação. Ora, então por que as estufas são quentes? Porque elas bloqueiam o movimento do ar. Todos sabemos do efeito refrescante proporcionado pela passagem do vento. Pois bem, a função da casa de vidro é impedir a troca de ar do interior da estufa com o meio externo, ou seja, as estufas são ambientes quentes porque são propositalmente mal ventiladas. Num ambiente mal ventilado, a energia ali presente, não importa qual seja sua origem, tem mais dificuldade para se dissipar, o que resulta inevitavelmente numa elevação das temperaturas em seu interior. 


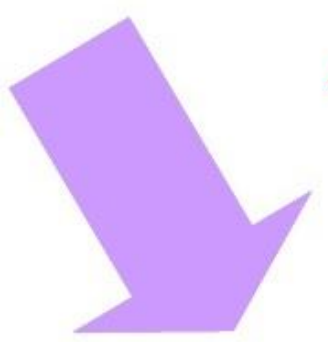

Radiação

solar

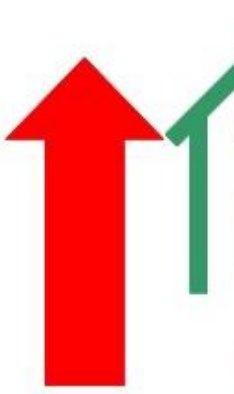

Radiação

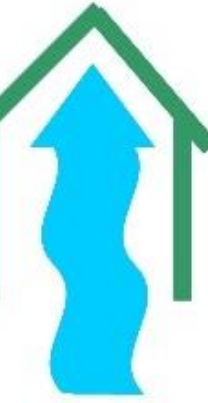

Dinâmica de fluidos

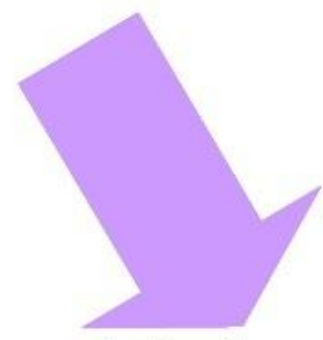

Radiação solar

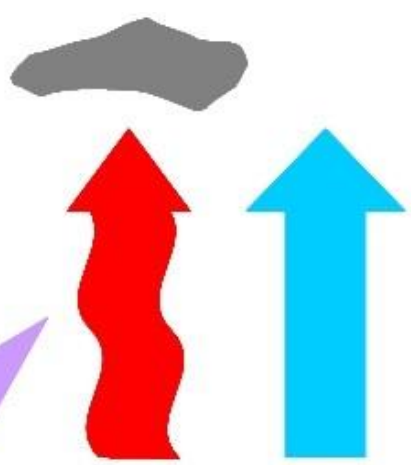

Radiação

Dinâmica de fluidos

Figura 2 - Esquerda: como as estufas efetivamente funcionam (resultados certos). Direita: o suposto efeito estufa, o que realmente ocorre na Terra (resultados incertos). (Essex; McKitrick, 2007, p. 126).

O que se passa com a Terra não é a mesma coisa. Os chamados gases estufa de fato bloqueiam a saída de radiação infravermelha, mas não bloqueiam a movimentação da atmosfera nem dos oceanos. Esses movimentos e todos os processos físicos a eles associados são a peça chave para a distribuição da energia pelo planeta. Como os gases estufa não tem poder sobre esses movimentos, eles também não tem poder sobre os fluxos de energia do planeta. Um exemplo: com o aquecimento do planeta provocado pelos gases estufa, poderá ocorrer maior evaporação da água dos oceanos, consequentemente maior formação de nuvens, que não só bloqueiam parte da entrada de radiação solar como, ao cair da chuva, liberam calor latente para a alta atmosfera, que se perde para o espaço. Ambos os processos contribuiriam para um resfriamento do planeta, e não para um aquecimento. Seria um resfriamento provocado por um aquecimento, um típico mecanismo de realimentação negativa. Se lembrarmos que os movimentos atmosféricos e oceânicos são essencialmente caóticos e que o superávit energético fornecido pelos gases estufa não se traduz apenas em energia térmica, mas também em energia cinética e muitas outras formas, segue-se que o resultado desse superávit energético sobre o sistema climático é essencialmente imprevisível. Ou seja, o lançamento de gases estufa pode tanto fazer a Terra aquecer, quanto resfriar, quanto não acontecer nada.

Podemos, porém, pensar que é exatamente porque o sistema climático é caótico e o resultado de nossas emissões é imprevisível que não deveríamos interferir sobre ele de forma alguma. Assim como os gases estufa podem resfriar o planeta, conforme 0 
raciocínio descrito acima, podem, sim, aquecê-lo, e aquecê-lo muito, fazendo-se concretizar os mais temidos cenários de mudanças climáticas. Esta, entretanto, é uma compreensão muito incompleta do funcionamento dos sistemas caóticos. Neste tipo de sistema, as noções de ação e de quantidade perdem sentido. Se o que conhecemos por ação pode provocar uma reação essencialmente imprevisível no sistema climático, nossa inação também pode provocar uma reação igualmente imprevisível. A inação também é uma ação. Da mesma forma, o tamanho da ação não tem uma relação direta e previsível com a reação. Uma ação grande pode provocar uma reação pequena, uma ação pequena pode provocar uma reação grande e ambas podem provocar nenhuma reação. Uma grande emissão de gases estufa pode provocar um grande aquecimento, um grande resfriamento ou não provocar nada, e os mesmos resultados podem ser obtidos em consequência de uma pequena emissão de gases estufa, assim como de nenhuma emissão.

\section{REFERÊNCIAS}

ESSEX, Christopher; MCKITRICK, Ross. Taken by storm: the troubled science, policy, and politics of global warming. Toronto, Key Porter Books, 2007.

IPCC. Climate change 2007: the physical science basis. Cambridge, New York; Cambridge University Press, 2007. 